\title{
A Retrospective Audit of Type 2 Diabetes Patients Prescribed Liraglutide in Real-Life Clinical Practice
}

\author{
Ciara M. Mulligan • Roy Harper $\cdot$ Janet Harding $\cdot$ \\ Werner Mcllwaine $\cdot$ Ann Petruckevitch • \\ Darren M. McLaughlin
}

To view enhanced content go to www.diabetestherapy-open.com

Received: March 26, 2013 / Published online: May 29, 2013

(C) The Author(s) 2013. This article is published with open access at Springerlink.com

\section{ABSTRACT}

Background: In phase 3 trials, the once-daily human glucagon-like peptide-1 analog liraglutide provided effective glycemic control with low rates of hypoglycemia, weight loss, and reduced systolic blood pressure (SBP) in patients with type 2 diabetes. Through a retrospective clinical audit, the authors aimed to assess the clinical effectiveness of liraglutide, from initiation to first hospital visit, when prescribed at a center in Northern Ireland.

Methods: Patients attending Ulster Hospital who were prescribed liraglutide (June 2009September 2010) and assessed both at baseline

C. M. Mulligan ( $₫) \cdot$ R. Harper · J. Harding ·

W. McIlwaine - D. M. McLaughlin

Diabetes Department, Ulster Hospital, Dundonald,

Belfast BT16 1RH, Northern Ireland, UK

e-mail: ciara.mulligan@setrust.hscni.net

A. Petruckevitch

CMR Effectiveness Team, Clinical, Medical and

Regulatory Department, Novo Nordisk, Crawley, UK

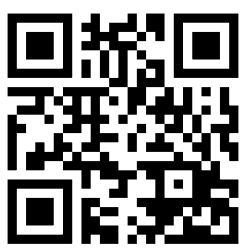

Enhanced content for this article is

available on the journal web site:

www.diabetestherapy-open.com and first post-initiation visit were included in the analysis. The primary endpoint was change in glycated hemoglobin $\left(\mathrm{HbA}_{1 \mathrm{c}}\right)$ from baseline. Weight, blood pressure, and frequency of hypoglycemic events were also assessed.

Results: Data from 193 patients are reported (baseline $\mathrm{HbA}_{1 \mathrm{c}}$ 9.0\%, mean age 55.8 years, diabetes duration 8.8 years, $66.8 \%$ male). Average time to first visit after initiation was 13.5 weeks, at which point 174 patients (90.2\%) were prescribed $1.2 \mathrm{mg}$ liraglutide. Mean change in $\mathrm{HbA}_{1 \mathrm{c}}$ from initiation to first visit was $-0.9 \%$, while mean body weight change was $-2.4 \mathrm{~kg}$ and change in SBP was $-2.0 \mathrm{mmHg}$. Transient gastrointestinal side effects were experienced by $11.9 \%$ of patients. The number of patients experiencing minor hypoglycemic events was low (5.7\%) and no major events were reported.

Conclusion: Data from clinical studies translate into clinical practice: liraglutide provided improved glycemic control after 13.5 weeks of treatment, accompanied by weight loss and low incidence of hypoglycemia.

Keywords: Audit; Glucagon-like peptide-1; Glycemic control; Liraglutide; Type 2 diabetes 


\section{INTRODUCTION}

In clinical trials of patients with type 2 diabetes, glucagon-like peptide-1 (GLP-1) receptor agonists have been shown to provide effective glycemic control when used in combination with oral antidiabetic drugs (OADs) [1]. However, data regarding the use of GLP-1 receptor agonists in clinical practice are scarce. Here, the authors report data from the use of the once-daily human GLP-1 analog liraglutide in clinical practice.

Liraglutide is a once-daily human GLP-1 analog with $97 \%$ amino acid sequence identity to native GLP-1 [2]. In phase 3 trials, liraglutide has been found to provide glycemic control alongside potential beneficial effects on body weight, reductions in systolic blood pressure (SBP), and improved beta-cell function [3-9]. Liraglutide treatment has also been found to be associated with a low risk of hypoglycemia, particularly when used without concomitant sulfonylurea treatment [3-9]. Liraglutide $1.2 \mathrm{mg}$ is recommended by the UK National Institute for Health and Clinical Excellence (NICE) for use in certain patients as second-line therapy (in combination with metformin or sulfonylurea) or third-line therapy (in combination with metformin + sulfonylurea, or metformin + thiazolidinedione) [10].

The authors aimed to assess the clinical effectiveness of liraglutide, from treatment initiation to first hospital visit, when prescribed at a center in Northern Ireland. The authors hypothesized that in a real-life clinical setting, despite the use of different background therapies, liraglutide treatment would result in comparable changes in $\mathrm{HbA}_{1 \mathrm{c}}$, body weight, and SBP to those observed in clinical trials.

\section{MATERIALS AND METHODS}

The authors assessed all patients who were prescribed liraglutide at Ulster Hospital from June 2009 to September 2010 and present data showing changes from baseline to the first hospital visit after initiation of liraglutide. In line with recommendations for initiating liraglutide and improving gastrointestinal (GI) tolerability, the starting dose of liraglutide was $0.6 \mathrm{mg}$ daily. After 1 week, the dose was increased to $1.2 \mathrm{mg}$ once daily. The primary endpoint assessed was change in glycated hemoglobin $\left(\mathrm{HbA}_{1 \mathrm{c}}\right)$ from baseline to first clinic visit after the initiation of liraglutide. Data on body weight, SBP, hypoglycemia, and GI side effects were also assessed. Error is standard deviation (SD) unless otherwise stated. Stata 10 (StataCorp, 2007) was used to calculate means (SD) by summary descriptive statistics after data manipulation [11]. No statistical tests were performed.

\section{RESULTS}

\section{Patient Demographics and Baseline Characteristics}

A total of 193 patients were included in the audit, 50 of whom (25.9\%) were prescribed liraglutide off-license with existing insulin regimens (off-license use of liraglutide was initiated on investigator request and it was their sole responsibility). Among patients taking insulin in combination with liraglutide, 13 used basal insulin at baseline, 27 used basalbolus regimens, and 10 used a premixed insulin. A total of $129(66.8 \%)$ patients were male. The mean (SD) patient age was 55.8 (9.7) years, and mean (SD) duration of diabetes was 8.8 (5.4) 
years. Mean (SD) $\mathrm{HbA}_{1 \mathrm{c}}$ was 9.0 (1.5)\%, SBP 133.5 (16.3) $\mathrm{mmHg}$, and diastolic blood pressure $75.2 \quad$ (9.5) $\mathrm{mmHg}$. Mean (SD) cholesterol levels were 3.98 (0.89) $\mathrm{mmol} / \mathrm{L}$, low-density lipoprotein cholesterol 1.89 (0.76) $\mathrm{mmol} / \mathrm{L}$, high-density lipoprotein cholesterol $\quad 1.06 \quad(0.25) \mathrm{mmol} / \mathrm{L}, \quad$ and triglyceride levels were $2.46(1.5) \mathrm{mmol} / \mathrm{L}$. In line with recommendations [10], liraglutide was initially prescribed at a dose of $0.6 \mathrm{mg}$ to improve GI tolerability and the dose could be escalated to $1.2 \mathrm{mg}$ after 1 week of treatment. The average time from treatment initiation to first post-initiation visit was 13.5 weeks. At the time of the first post-initiation visit, 174 (90.2\%) patients were prescribed liraglutide $1.2 \mathrm{mg}$ and 19 (9.8\%) were receiving liraglutide $0.6 \mathrm{mg}$. No patients were prescribed liraglutide $1.8 \mathrm{mg}$ at the first post-initiation visit.

\section{Efficacy}

From baseline, mean (SD) $\mathrm{HbA}_{1 \mathrm{c}}$ in the overall patient group $(n=193)$ reduced by $0.9(1.1) \%$, from $9.0 \quad(1.5) \%$ to $8.1 \quad(1.4) \% \quad$ (75 and $65 \mathrm{mmol} / \mathrm{mol}$, respectively; Table 1). Mean (SD) body weight decreased by $2.4(7.3) \mathrm{kg}$ from a baseline of 116.7 (24.0) $\mathrm{kg}$ to 114.4 (22.8) $\mathrm{kg}$ at the first post-initiation visit. In addition, mean (SD) SBP was reduced by 2.0 $( \pm 17.1) \mathrm{mmHg}$ from a baseline of 133.5 $( \pm 16.3) \mathrm{mmHg}$ to $131.0( \pm 16.2) \mathrm{mmHg}$ at the first post-initiation visit. For patients using insulin $(n=50)$, the average insulin dose remained stable: mean basal doses were 70.6 and $70.0 \mathrm{U}$, and bolus doses were 79.4 and $76.3 \mathrm{U}$, at baseline and first visit, respectively. The insulin-treated group had a mean (SD) baseline $\mathrm{HbA}_{1 \mathrm{c}}$ of $9.2( \pm 1.3) \%(77 \mathrm{mmol} / \mathrm{mol})$ and a $0.8( \pm 1.1) \%$ reduction was observed at the first post-initiation visit.
Table 1 Outcomes in patients prescribed liraglutide at the Ulster Hospital

\begin{tabular}{lclc}
\hline $\begin{array}{l}\text { Efficacy } \\
\text { endpoints }\end{array}$ & Baseline & $\begin{array}{l}\text { First post- } \\
\text { initiation visit }\end{array}$ & $\begin{array}{l}\text { Change } \\
\text { from } \\
\text { baseline }\end{array}$ \\
\hline $\mathrm{HbA}_{1 \mathrm{c}}(\%)$ & $9.0(1.5)$ & $8.1(1.4)[65]$ & $-0.9(1.1)$ \\
{$[\mathrm{mmol} / \mathrm{mol}]$} & {$[75]$} & & {$[-9.8]$} \\
Body weight & 116.7 & $114.4(22.8)$ & $-2.4(7.3)$ \\
$(\mathrm{kg})$ & $(24.0)$ & & \\
$\mathrm{SBP}(\mathrm{mmHg})$ & 133.5 & $131.0(16.2)$ & -2.0 \\
& $(16.3)$ & & $(17.1)$ \\
& 75.2 & $75.5(10.3)$ & $0.0(10.4)$ \\
DBP (mmHg) & $(9.5)$ & & Incidence (\%) \\
\hline Safety endpoints & & 11.9 \\
\hline Gastrointestinal effects & & 5.7 \\
Minor hypoglycemia & &
\end{tabular}

Errors are $\mathrm{SD}$

$H b A_{1 c}$ Glycosylated hemoglobin, $D B P$ diastolic blood pressure, $S B P$ systolic blood pressure

\section{Tolerability}

Twenty-three (11.9\%) patients experienced GI effects, a known side effect of liraglutide, and these were mainly transient. Eleven (5.7\%) patients experienced minor hypoglycemia, nine $(81.8 \%)$ of these were taking concomitant sulfonylureas and one $(0.09 \%)$ was taking basal insulin.

\section{DISCUSSION}

The changes observed here are comparable to those in phase 3 trials of liraglutide $1.2 \mathrm{mg}$ in combination with OADs, in which $\mathrm{HbA}_{1 \mathrm{c}}$ decreases ranged from 1.0 to $1.5 \%$, weight change from +0.3 to $-2.9 \mathrm{~kg}$, and SBP decreases from 0.6 to $6.7 \mathrm{mmHg}$ following 26-week treatment $[3,4,6$, 9]. At 5.7\%, the occurrence of minor hypoglycemia in this study 
also reflects data from phase 3 trials of patients using liraglutide $1.2 \mathrm{mg}$ in combination with OADs [3, 4, 6, 9]. Limitations of the present study include its single-arm observational design, the absence of a fixed timeline for the first visit, and the fact that it was conducted at a single center. Furthermore, patients received concomitant medications that may have affected the measured outcomes, and these medications may have changed during the course of the study.

In this study, the insulin dose did not need to be reduced in patients who were using liraglutide with insulin. This observation is likely to be a reflection of the fact that initial glycemic control in these patients was poor. A clinical trial of the GLP-1 receptor agonist exenatide twice daily in combination with insulin also showed reductions in $\mathrm{HbA}_{1 \mathrm{c}}$ [12], and another trial exploring the sequential addition to metformin of liraglutide and then insulin detemir also reported good glycemic control, sustained weight loss, and low rates of hypoglycemia [13]. Based on these data, in Europe, exenatide twice daily is licensed for use in combination with basal insulin, and insulin detemir can be added to existing liraglutide therapy $[14,15]$. It should be remembered that the addition of liraglutide to basal insulin is off-license, but if the combination is prescribed, the insulin dose should be monitored to minimize hypoglycemia; in the trial combining exenatide with insulin, patients with $\mathrm{HbA}_{1 \mathrm{c}} \leq 8.0 \%(64 \mathrm{mmol} / \mathrm{mol})$ had their insulin dose reduced by $20 \%$ during the addition of exenatide treatment [10].

In conclusion, the data reported here show that results from clinical trials of liraglutide translate into real-life clinical practice. Liraglutide was well tolerated with a low incidence of hypoglycemia. Liraglutide improved glycemic control, body weight, and SBP, indicating that liraglutide is effective in a real-life setting.

\section{ACKNOWLEDGMENTS}

Sponsorship for this study and article processing charges was funded by Novo Nordisk. Editorial assistance in the preparation of this manuscript was provided by Helen Stimpson and David Harvey of Watermeadow Medical. Support for this assistance was funded by Novo Nordisk. Novo Nordisk was involved in reviewing draft versions for medical accuracy.

Dr C. M. Mulligan is the guarantor for this article, and takes responsibility for the integrity of the work as a whole.

Author contributions. CM, data collection and editing of manuscript; $\mathrm{RH}$, assistance with data collection and editing of manuscript. AP, data analyses and manuscript editing to ensure correct interpretation of statistical analyses. $\mathrm{JH}$, WM and DM were all involved in editing and reviewing the manuscript. $\mathrm{CM}$ is the guarantor for this article.

Conflict of interest. CM has been reimbursed by Novo Nordisk, Takeda and GlaxoSmithKline for attending several conferences, and has received speaker fees from Novo Nordisk, Eli Lilly and Bristol-Myers Squibb. WJM has been reimbursed by Novo Nordisk for attending educational conferences. DML has been reimbursed by Novo Nordisk, Takeda and GlaxoSmithKline for attending several conferences, and has received speaker fees from Merck Sharp \& Dohme, Pfizer, SanofiAventis, Novo Nordisk, Eli Lilly, Novartis, Takeda and GlaxoSmithKline. At the time of writing, AP was employed by, and owned shares 
in, Novo Nordisk. RH and JH declare no conflict of interest. Writing assistance for this manuscript was supported by Novo Nordisk.

Compliance with Ethics Guidelines. This article does not contain any studies with human or animal subjects performed by any of the authors.

Open Access. This article is distributed under the terms of the Creative Commons Attribution Noncommercial License which permits any noncommercial use, distribution, and reproduction in any medium, provided the original author(s) and the source are credited.

\section{REFERENCES}

1. Jellinger P. Focus on incretin-based therapies: targeting the core defects of type 2 diabetes. Postgrad Med. 2011;123:53-65.

2. Knudsen LB. Glucagon-like peptide-1: the basis of a new class of treatment for type 2 diabetes. J Med Chem. 2004;47:4128-34.

3. Marre M, Shaw J, Brändle M, et al. LEAD-1 SU study group. Liraglutide, a once-daily human GLP-1 analogue, added to a sulphonylurea over 26 weeks produces greater improvements in glycaemic and weight control compared with adding rosiglitazone or placebo in subjects with type 2 diabetes (LEAD-1 SU). Diabet Med. 2009;26:268-78.

4. Nauck MA, Frid A, Hermansen K, et al. LEAD-2 Study Group. Efficacy and safety comparison of liraglutide, glimepiride, and placebo, all in combination with metformin in type 2 diabetes. Diabetes Care. 2009;32:84-90.

5. Garber A, Henry R, Ratner R, et al. LEAD-3 (Mono) Study Group. Liraglutide versus glimepiride monotherapy for type 2 diabetes (LEAD-3 Mono): a randomised, 52-week, phase III, double-blind, parallel-treatment trial. Lancet. 2009;373:473-81.

6. Zinman B, Gerich J, Buse JB, et al. LEAD-4 Study Investigators. Efficacy and safety of the human glucagon-like peptide-1 analog liraglutide in combination with metformin and thiazolidinedione in patients with type 2 diabetes (LEAD-4 Met + TZD). Diabetes Care. 2009;32: 1224-30.

7. Russell-Jones D, Vaag A, Schmitz O, et al. Liraglutide Effect and Action in Diabetes 5 (LEAD5) met + SU Study Group. Liraglutide vs. insulin glargine and placebo in combination with metformin and sulfonylurea therapy in type 2 diabetes mellitus (LEAD-5 met + SU): a randomised controlled trial. Diabetologia. 2009;52: 2046-55.

8. Buse JB, Rosenstock J, Sesti G, et al. LEAD-6 Study Group. Liraglutide once a day versus exenatide twice a day for type 2 diabetes: a 26-week randomised, parallel-group, multinational, openlabel trial (LEAD-6). Lancet. 2009;374:39-47.

9. Pratley RE, Nauck M, Bailey T, et al. 1860-LIRA-DPP4 Study Group. Liraglutide versus sitagliptin for patients with type 2 diabetes who did not have adequate glycaemic control with metformin: a 26-week, randomised, parallel-group, open-label trial. Lancet. 2010;375:1447-56.

10. NICE. TA203: Liraglutide for the treatment of type 2 diabetes mellitus. 2010. http://www.nice.org.uk/ nicemedia/live/13248/51259/51259.pdf. Accessed 29 Jan 2013.

11. StataCorp. 2007. Stata Statistical Software: Release 10. College Station, TX: StataCorp LP.

12. Buse JB, Bergenstal RM, Glass LC, et al. Use of twicedaily exenatide in basal insulin-treated patients with type 2 diabetes. Ann Intern Med. 2011;154: 103-12.

13. DeVries JH, Bain SC, Rodbard HW, et al. LiraglutideDetemir Study Group. Sequential intensification of metformin treatment in type 2 diabetes with liraglutide followed by randomized addition of basal insulin prompted by A1C targets. Diabetes Care. 2012;35:1446-54.

14. Amylin Pharmaceuticals. Byetta Summary of Product Characteristics. July 2012. http://www.ema. europa.eu/docs/en_GB/document_library/EPAR_ Product_Information/human/000698/WC5000518 45.pdf. Accessed 29 Jan 2013.

15. Novo Nordisk. Levemir Summary of Product Characteristics. January 2012. http://www.ema. europa.eu/docs/en_GB/document_library/EPAR_ Product_Information/human/000528/WC500036662. pdf. Accessed 29 Jan 2013. 